\title{
Extrapleural hematoma: when is surgery indicated?
}

\author{
A.S. Poyraz, D. Kilic, B. Gultekin, M. Ozulku, A. Hatipoglu
}

ABSTRACT: Extrapleural hematoma: when is surgery indicated? A.S. Poyraz, D. Kilic, B. Gultekin, M. Ozulku, A. Hatipoglu.

Extrapleural haematoma (EH) is a rare clinical condition of which four cases are presented. Different etiologies were encountered. Identical findings were found on the chest X-ray. Two cases were secondary to spontaneous rib fracture and the other two were iatrogenic. Surgical exploration was necessary in one patient following pleural biopsy. Medical treatment and clinical observation were the treatment of choice in the remaining three stable patients. Monaldi Arch Chest Dis 2005; 63: 3, 166-169.

Keywords: Haematoma, extrapleural haematoma, percutaneous catheterisation, pleural biopsy, spontaneous rib fracture.

Department of Thoracic and Cardiovascular Surgery, Faculty of Medicine, Baskent University, Ankara, Turkey.

Correspondence: A. Serhan Poyraz, Department of Thoracic and Cardiovascular Surgery, Faculty of Medicine, Baskent University, Konya, Turkey; e-mail: ahmetserhanpoyraz@hotmail.com

\section{Introduction}

To our knowledge only a few reports of extrapleural haematoma (EH) with different etiology have been presented in literature. We describe four patients with EH referred to our department during a 3-year period, with different etiological factors - both spontaneous and iatrogenic - and with identical findings on the chest X-ray.

\section{Case Reports}

\section{Patient 1}

A 63-year-old woman was scheduled to undergo dialysis because of end-stage renal disease. A central venous catheter was inserted in the right subclavian vein, but it was removed because of insufficient flow. Haematoma occurred on the insertion site. A posteroanterior chest radiograph revealed an intense, round, homogeneous shadow, $6 \times 5 \mathrm{~cm}$ in size, with a broad basis arising from the upper chest wall (fig. 1a). Lateral film was suggesting an extrapleural process (fig.1b). A chest computed tomographic (CT) scan revealed a loculated extrapleural effusion in the right hemithorax (fig. 1c). EH in this case occurred after an attempt to cannulate the subclavian vein. The haemoglobin level was stable and the patient was merely observed and no other treatment was given. Followup chest films showed spontaneous regression and resolution of the haematoma (fig. 1d).

\section{Patient 2}

A 55-year-old man presented with pain in the upper chest after forceful paroxysmal coughing. On examination, he had mild tenderness over his right chest. There was no history of thoracic trau- ma and etiologic factor was distant osteopenia due to chronic renal disease. A chest roentgenogram revealed spontaneous fracture of $5^{\text {th }}$ right rib and a $4 \times 4 \mathrm{~cm}$ homogeneous density having in the middle zone of the right hemithorax suggesting an extrapleural process. The patient was admitted to the hospital for observation. He was symptom-free after spontaneous resolution after one month.

\section{Patient 3}

A 52-year-old woman was diagnosed with diabetes mellitus, chronic renal failure and thickening of the left pleura. To evaluate the latter a pleural biopsy was performed. The following day breath sounds were diminished at the base of the left lung and haemoglobin levels started to decrease necessitating blood transfusion and vasopressor therapy. Chest X-ray revealed a poorly delineated left lung field and a haemothorax was suspected. Initially, the patient was thought to have an intrapleural haematoma, which was treated by closed drainage. However, only an extremely small amount of blood-like fluid was evacuated. She was taken into surgery and a left anterolateral mini-thoracotomy with partial resection of the $6^{\text {th }}$ rib was performed. The operative findings did not support a diagnosis of an intrathoracic loculated pleural haematoma. An extrapleural haematoma measuring $10 \times 7 \mathrm{~cm}$ diameter was found in the left extrapleural space. The haematoma was evacuated. No bleeding vessel was found. The patient was discharged from hospital without any further complications.

\section{Patient 4}

A 32 year-old man suffering from chronic cough presented to the emergency department with 


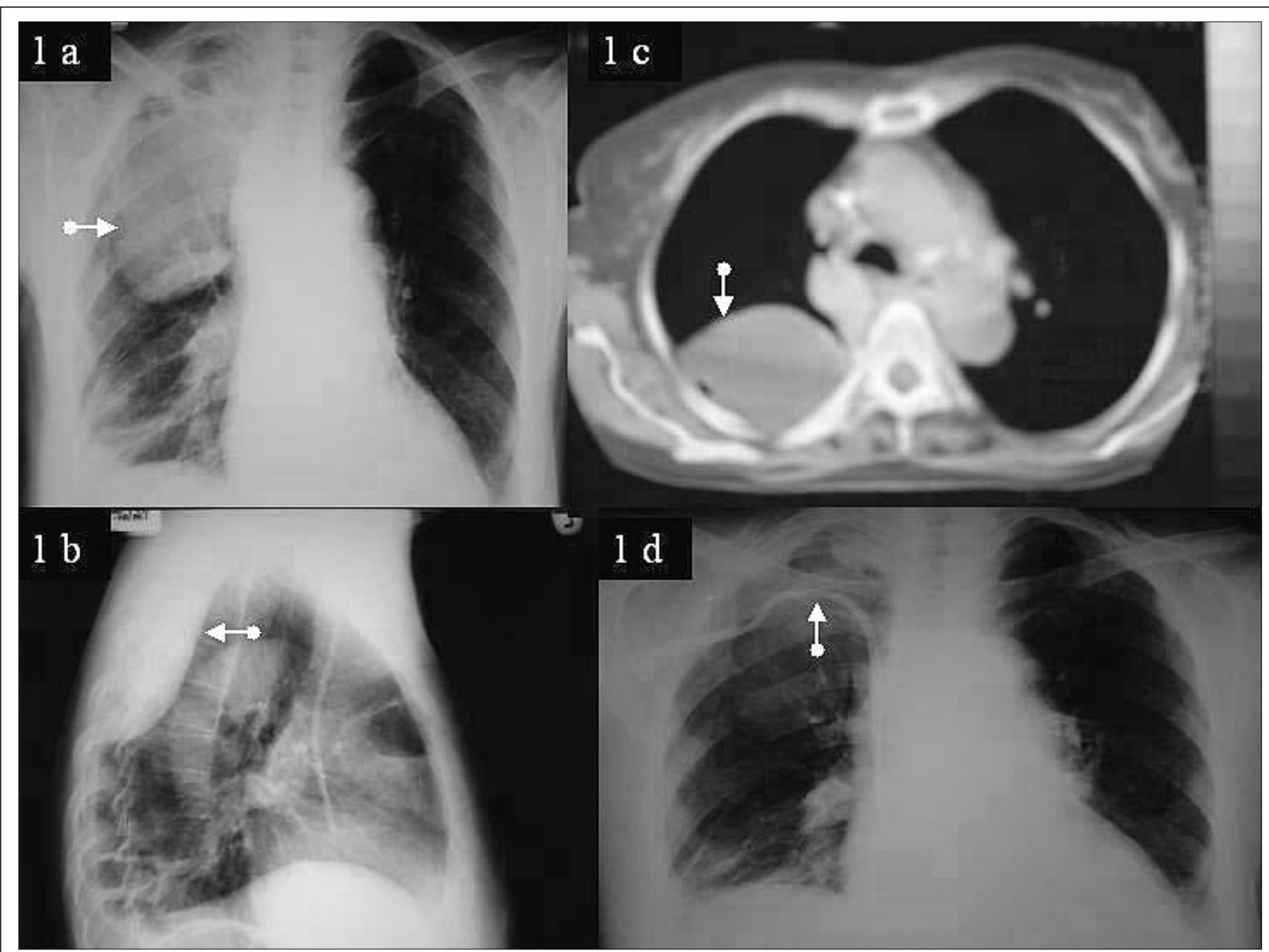

Fig. 1 a-d. - Patient 1. (a) Postero-anterior chest roentgenogram revealing an intense, round, homogeneous shadow, $6 x 5 \mathrm{~cm}$, in the upper zone (arrow). (b) Lateral chest roentgenogram showing a 7x4 cm intense, homogeneous density, with a broad basis arising from the chest wall, situated near the vertebral column (arrow). (c) Chest CT demonstrating a loculated extrapleural effusion in the right hemithorax (arrow). (d) Follow-up chest X-ray revealing no evidence of any residual disease. A catheter is present in the right subclavian vein (arrow).

upper chest pain of sudden onset associated with dyspnea. There was no specific etiologic factor besides forceful paroxysmal coughing due to influenza. Physical examination revealed a $4 \times 4 \mathrm{~cm}$ tender area overlying the right 7 th rib. Chest X-ray film revealed a $5 \times 3 \mathrm{~cm}$ opacity with a sharply defined convex contour in the lower chest facing the lung. Superior and inferior margins were tapered suggesting an extrapleural process with an $\mathrm{EH}$ in relation to a spontaneous fracture of 7 th rib (fig. $2 \mathrm{a}$ ). Follow-up chest films showed spontaneous resolution after 4 days (fig. 2b).

\section{Discussion}

EH may occur spontaneously or secondary to various etiologic factors. Rashid et al. described a simple etiologic classification of $\mathrm{EH}$ which was divided in 3 groups: spontaneous, iatrogenic and traumatic [1]. There are a few case reports in the literature to date in which the etiology and treatment modalities of EH specifically discussed [1-8] (table 1). Three of these reports deal with cases of primary traumatic (TEH). On reviewing the literature, cases of $\mathrm{EH}$ as a complication of central venous catheterisation (iatrogenic) are reported as isolated events [2-4]. In our series both iatrogenic and spontaneous EH were present. To our knowl- edge, this is the first report of $\mathrm{EH}$ as a result of spontaneous rib fracture and pleural biopsy.

Rashid et al. explain the mechanism of $\mathrm{EH}$ as follows: a specific procedure such as cannulation of the subclavian vein, causes rupture of blood vessels of the thoracic wall and the blood cannot escape into pleural space as the thickened parietal pleura prevents its rupture resulting in $\mathrm{EH}[1]$.

Clinical manifestations of $\mathrm{EH}$ include haemorrhage, pain, and dyspnea as shown in our series.

The diagnosis of $\mathrm{EH}$ can be challenging. In particular, when differential diagnosis between loculated intrapleural or extrapleural haematoma is difficult, a chest CT is recommended. With prolonged extrapleural compression of the lung, changes in the pulmonary parenchyma may be observed. We recognized all our cases using chest roentgenogram. In cases of spontaneous EH the absence of penetration of the pleural cavity and absence of a pleural reaction may result in a pleural cavity without effusion. Delay in diagnosis and treatment may have serious, early consequences, with massive haemorrhaging from the large vessels of the upper thorax, the most serious and potentially life-threatening complication. Huge EH might cause ventilatory and circulatory disturbances and even death. 


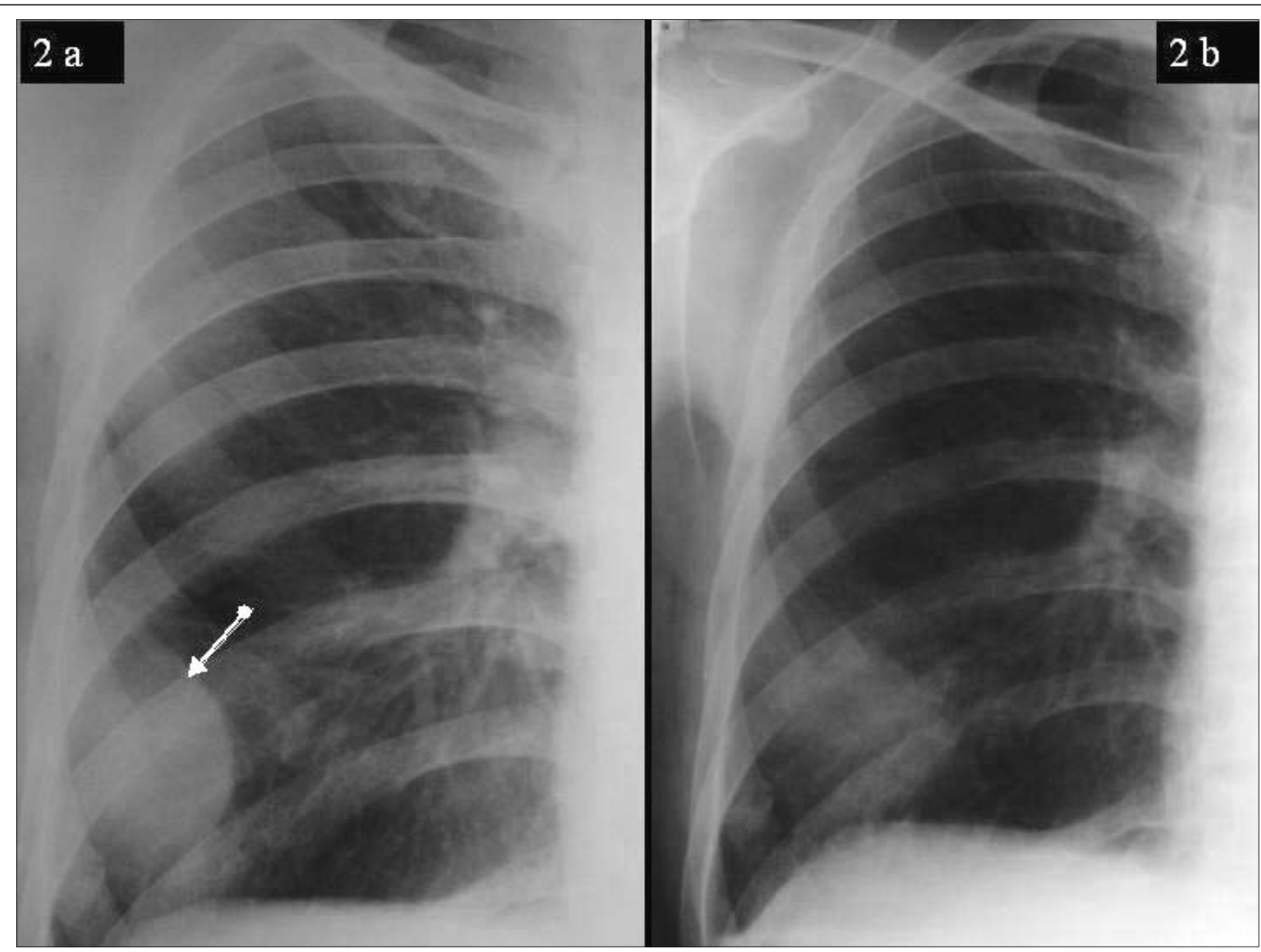

Fig. 2 a, b. - Patient 4. (a) Postero-anterior chest roentgenogram revealing an opacity of $5 \times 3 \mathrm{~cm}$ in the lower chest with a sharply defined convex contour facing the lung (arrow) with tapered superior and inferior margins together with a fracture of the 7th rib. (b) Chest roentgenogram showing spontaneous resolution after 4 days.

Table 1. - Different etiology and treatment modalities presented for EH presented in the literature to date

\begin{tabular}{|c|c|c|c|c|}
\hline Reference & Year & Patient Number & Etiology & Treatment and outcome \\
\hline Rashid MA (1) & 2000 & 34 & Chest trauma & $\begin{array}{l}\text { Spontaneous resolution in } 33 \\
\text { patients, thoracotomy in one patient, } \\
\text { postoperative course was uneventful }\end{array}$ \\
\hline Brandi LS (2) & 1984 & 1 & $\begin{array}{l}\text { After attempted catheterization } \\
\text { of the internal jugular vein }\end{array}$ & Spontaneous resolution \\
\hline Ueki R (3) & 2000 & 1 & $\begin{array}{l}\text { After attempted catheterization } \\
\text { of the right jugular vein }\end{array}$ & Spontaneous resolution \\
\hline Kay J (4) & 1987 & 1 & $\begin{array}{l}\text { After attempted catheterization } \\
\text { of the internal jugular vein }\end{array}$ & $\begin{array}{l}\text { Neck dissection and median } \\
\text { sternotomy, postoperative course } \\
\text { was uneventful }\end{array}$ \\
\hline Mingoli A (5) & 2004 & 1 & $\begin{array}{l}\text { After thoracic blunt trauma and rib } \\
\text { fractures in an anti-coagulated } \\
\text { patient (Trauma) }\end{array}$ & $\begin{array}{l}\text { Emergency surgical treatment, } \\
\text { postoperative course was uneventful }\end{array}$ \\
\hline Konen O (6) & 2002 & 2 & After coronary surgery & $\begin{array}{l}\text { Spontaneous resolution in both } \\
\text { patients }\end{array}$ \\
\hline Moulin G (7) & 1992 & 1 & $\begin{array}{l}\text { Fracture of the body of the eleventh } \\
\text { thoracic vertebra (Trauma) }\end{array}$ & $\begin{array}{l}\text { Surgical treatment, postoperative } \\
\text { course was uneventful }\end{array}$ \\
\hline Present cases & 2005 & 4 & $\begin{array}{l}\text { Spontaneous rib fracture (2), } \\
\text { pleural biopsy (1), after attempted } \\
\text { catheterization of the right } \\
\text { subclavian vein (1) }\end{array}$ & $\begin{array}{l}\text { Spontaneous resolution in } 3 \text { patients } \\
\text { and limited thoracotomy in one } \\
\text { patient, postoperative course was } \\
\text { uneventful }\end{array}$ \\
\hline
\end{tabular}


The differential diagnosis includes encapsulated intrapleural effusion, pleural and extrapleural tumours, pleural plaque, peripheral lung tumor, and plombage, e.g. oleothorax, round atelectasis and mesothelial cyst.

Treatment for EH has been established in literature. Decision-making criteria in surgery are closely related to the clinical condition of patient. In our series, spontaneous complete resolution was observed in three patients whose medical therapies were successful. Closed drainage failed, and a limited thoracotomy to evacuate the haematoma was performed in the fourth patient. The EH may necessitate blood transfusion when an active bleeding vessel is present $[4,5]$. Because of poor visualisation as a cause of no anatomical cavity, Rashid MA et al. suggested that video-assisted thoracic surgery was not suited to approach and manage the TEH [8]. Unless large sizes, TEH should be considered a relative major contraindication to VATS. This approach is very important in saving time and money. However, we believe that VATS could be useful in exploring the pleural cavity, open up the parietal pleura, drain the haematoma and look for a bleeding vessel. Thus, in the case of an unsuccessful procedure, conversion to thoracotomy is possible. Another treatment option after a CT scan of the chest is obtained, is to insert a drain in the extrapleural space under CT guidance and in case of insufficient drainage due to clotted haematoma, to start thrombolytic treatment as is done for a retained haemothorax.
In conclusion, medical therapy and clinical observations are the treatment of choice in a stable patient in case of a small haematoma. Thoracotomy may be necessary in the presence of a complication such as massive haemorrhages, persisting and large haematomas and in cases of insufficient drainage.

\section{References}

1. Rashid MA, Wikstrom T, Ortenwall P. Nomenclature, classification, and significance of traumatic extrapleural hematoma. J Trauma 2000; 49: 286-290.

2. Brandi LS, Mosca F, Carmellini M, Nannoni L, Comite C, Manfrini M. An unusual complication of percutaneous catheterization of the internal jugular vein. Acta Anaesthesiol Belg 1984; 35: 231-236.

3. Ueki R, Okutani R, Fukushima A, Kurehara H, Sasaki $\mathrm{K}$, Tashiro C. Iatrogenic extrapleural hematoma [abstract]. Masui 2000; 49: 37-39.

4. Kay J, Goodman LR, Gurney J. Extrapleural hematoma: a recognizable complication of central venous pressure monitoring. J Clin Monit 1987; 3: 64-66.

5. Mingoli A, Assenza M, Petroni R, et al. Large extrapleural hematoma in an anticoagulated patient after a thoracic blunt trauma. Ann Ital Chir 2004; 75 (1): 83-5.

6. Konen O, Hertz M, Klein HO, Konen E, Zissin R. Extrapleural hematoma as an unexpected finding on a follow-up chest X-ray after coronary surgery. Eur J Radiol 2002; 44 (3): 225-7.

7. Moulin G, Bartoli JM, Fighiera M, et al. Extrapleural hematoma. J Radiol 1992; 73 (5): 327-30.

8. Rashid MA. Value of video-assisted thoracic surgery in traumatic extrapleural hematoma. Thorac Cardiovasc Surg 1999; 47: 255-257.

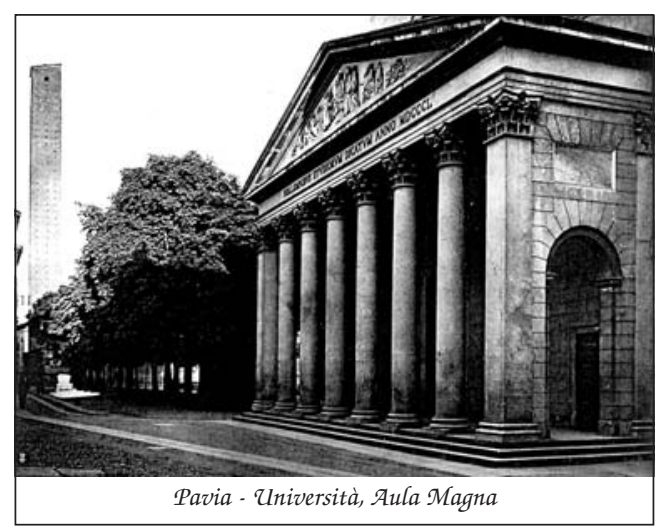

